\title{
AN ANTHOLOGY OF THE DISTINGUISHED ACHIEVEMENTS IN SCIENCE AND TECHNIQUE. PART 46: THERMONUCLEAR POWER ENGINEERING. THERMONUCLEAR REACTORS AND POWER PLANTS: RETROSPECTIVE VIEW OF INVESTIGATIONS OF THE CONTROLLED THERMONUCLEAR SYNTHESIS, THEIR STATE-OF-THE-ART AND FUTURE
}

Purpose. Preparation of brief scientific and technical review about the retrospective view of investigations, state-of-the art, problems and possible prospects of development in the world of thermonuclear power engineering. Methodology. Known scientific methods of collection, analysis and analytical treatment of the opened scientific and technical information of world level in area of the controlled thermonuclear synthesis (CTS) and thermonuclear power engineering, resulted in scientific monographs, journals and internet reports. Results. A brief analytical scientific and technical review is resulted about the retrospective view of researches, modern state, basic achievements, existent problems and possible prospects of development of thermonuclear power engineering in the leading countries of the world. Nuclear physical bases of process of flowing of CTS are resulted in mixture of light nuclei. Information is presented about the results of the initial and modern stages of world researches in area of CTS. Basic constructions and technical descriptions of thermonuclear reactors (TNR), utilizing the magnetic and inertia withholding of hot plasma are described. World progress is analyzed in area of development, creation and research of experimental TNR, being based on the systems of withholding of hot plasma in toroidal magnetic "traps» (options: tokamaks and stellarators) and inertia systems of laser-impulse technology of microscopic explosions of targets-capsules of thermonuclear fuel. Information is resulted about the basic types of thermonuclear fuel, which can be used in the duty cycles of TNR, and safety of TNR. The basic systems and devices of the largest in the world of experimental TNR-tokamak of ITER type (with a reference cost of EUR 15 billion and term of putting into an experimental operation in 2025), erected now within the framework of international project in France are described. Basic problems are indicated in area of CTS in experimental TNR and creations in the future of the thermonuclear power plants (TNPP). The important role of TNPP and thermonuclear power engineering is marked on the whole in providing of humanity in a long-term prospect electric energy. Originality. Certain systematization of the scientific and technical materials touching the problem of CTS of light nuclei and practical application in the peaceful aims of thermonuclear energy known from the sources opened in outer informative space is executed. It is shown on the basis of approach of the systems, that, in spite of row of existent technical problems in area of creation of industrial TNR and practical commercial capture thermonuclear energy, thermonuclear power engineering has an important value for providing in remote future electric energy of all of humanity. Practical value. Scientific popularization and deepening for the students of technical universities, engineering, technical and scientific workers, working in the power sector of economy, scientific and technical knowledge in area of CTS and thermonuclear power engineering, extending their scientific range of interests and further development of scientific and technical progress in society. References 29, figures 16, tables 2.

Key words: thermonuclear synthesis and reactor, thermonuclear power engineering, tokamak, stellarator, laser-impulse reactor, safety of thermonuclear reactor, thermonuclear power plant of the future, problems and possible prospects of development of world thermonuclear power engineering.

Приведен научно-технический обзор о ретроспективе исследований в ведущих странах мира управляемого термоядерного синтеза (УТС) легких ядер, современном состоянии разработок и возможных перспективах мирового развития наукоемкой техники в области термоядерной энергетики. Приведены ядерно-физические основы процесса протекания УТС в смеси легких ядер. Представлены данные о результатах начального и современного этапов исследований в области УТС. Описаны основные конструкции и технические характеристики термоядерных реакторов (ТЯР), использующих магнитное и инерционное удерэсание горячей плазмы. Проанализирован мировой прогресс в области разработки, создания и исследования экспериментальных ТЯР, базирующихся на системах удержания горячей плазмы в тороидальных магнитных «ловуиках》 (установки-токамаки и стеллараторы) и инерционных системах лазерно-импульсной технологии микровзрывов мищеней-капсул термоядерного топлива. Приведены данные об основных видах термоядерного топлива, которое может применяться в рабочих циклах ТЯР, и безопасности ТЯР. Указаны основные проблемы в области УТС для экспериментальных ТЯР и создания в будущем термоядерных электрических станций (ТЯЭС). Отмечена важная роль ТЯЭС и термоядерной энергетики в обеспечении человечества в долгосрочной перспективе электроэнергией. Библ. 29, рис. 16, табл. 2.

Ключевые слова: термоядерный синтез и реактор, термоядерная энергетика, токамак, стелларатор, лазерноимпульсный реактор, безопасность термоядерного реактора, термоядерная электрическая станция будущего, проблемы и возможные перспективы развития мировой термоядерной энергетики.

Introduction. From the world history of development on the planet Earth of modern civilization, it is clear that the needs of mankind in various types of energy are steadily increasing from year to year. In this regard, earthlings objectively face common planetary questions: how to satisfy the growing population's growing energy needs of people and industries around the world and on what principles to create further powerful new and safe artificial energy sources? For several centuries, the main source of both thermal and electrical energy for the inhabitants of the Earth has been the use (as a rule, combustion) of planetary reserves of natural fossil fuels - wood, coal, oil and gas. It is known that the reserves of this fuel on our planet are very limited. It is believed that by 2050 energy production in the world will 
increase by about three times compared with its current level and will be about $10^{21} \mathrm{~J} /$ year [1]. Therefore, in the foreseeable future, such a source of energy as fossil fuels will have to be replaced by earthlings with other sources of energy and, accordingly, with other types of its production. In this regard, at present, nuclear power [2] and alternative energy with its renewable energy sources [3] have been actively introduced into the production of thermal and electrical energy throughout the world. According to reputable energy specialists, alternative energy is able to meet the energy needs of humanity only in a relatively small fraction of energy (now this share in the world does not exceed $10 \%$ [3]). Therefore, objectively nuclear power remains for us the main candidate for the energy of the near future [1]. At present, nuclear physicists and power engineers have mastered only nuclear fission reactions of heavy nuclei of a number of isotopes of such radioactive chemical elements as uranium ${ }_{92}^{238} \mathrm{U}$, plutonium ${ }_{94}^{244} \mathrm{Pu}$, and thorium ${ }_{90}^{232} \mathrm{Th}$ in this complex energy sector on an industrial scale [2]. These reactions are widely used at modern high-power nuclear power plants (NPPs) based on the use of nuclear reactors (NRs) operating on slow or fast neutrons in their technological cycle [2, 4]. A significant disadvantage of NRs is the presence from their work of long-lived radioactive waste in large quantities, representing a huge world problem. Huge financial resources are spent on disposal and safe storage of this waste in the world. In addition, this waste for tens of thousands of years poses a serious environmental threat to all life on Earth. Taking into account these features of the operation of nuclear radiation at nuclear power plants, nuclear physicists since the 1950s turned their attention to thermonuclear synthesis reactions occurring in thermonuclear reactors (TNRs). The main and fundamental difference of these nuclear synthesis reactions in the TNR from nuclear fission reactions in the NR is the absence of long-lived radioactive waste from the TNR operation. It is believed that after stopping the TNR, the induced radioactivity of the refractory walls of the protective blanket in its core will decrease in time to safe levels for $\sim 30$ years [1]. In addition, there are inexhaustible fuel reserves on the Earth for thermonuclear synthesis reactions. Despite all the difficulties of the implementation of controlled thermonuclear synthesis (CTS) of light chemical elements (for example, such hydrogen ${ }_{1}^{1} \mathrm{H}$ (protium) isotopes as deuterium $\mathrm{D}-{ }_{1}^{2} \mathrm{H}$ and tritium $\mathrm{T}-{ }_{1}^{3} \mathrm{H}$ [4] in the TNR, in the mid-1950s leading nuclear countries of the world, including the USSR, the USA, the UK and France, to launch large-scale studies on CTS $[1,5,6]$. Add to the above that by this time in the USA and the USSR for military purposes successful tests of the first powerful hydrogen charges and bombs [1, 7] used explosive-type thermonuclear reactions and confirmed the principal possibility of the realization in terrestrial conditions of thermonuclear deuterium D and Tritium T synthesis were carried out.

The goal of the paper is preparation of a scientific and technical review of a retrospective of research, the current state, problems and possible prospects for the development of thermonuclear energy in the world.
1. Brief fundamentals of the physics of thermonuclear synthesis of light nuclei in the TNR. To begin with, let us point out that CTS is a synthesis of heavier atomic nuclei from less light nuclei, nonexplosive in the macrovolume of a substance, in order to obtain energy $[4,6]$. In accordance with the laws of nuclear physics, energy in CTS is released due to the mass defect of the nuclei participating in it - the mass of the resulting nuclei and particles turns out to be less than the mass of the original nuclei [4]. Applying to the CTS the law of energy conservation and the Einstein principle of equivalence of mass and energy, we can verify the reliability of the physical fact of the release of the energy of a strong interaction in CTS. So, for the nuclear reaction of the synthesis of deuterium D and tritium T (Fig. 1), proceeding according to the scheme

$$
{ }_{1}^{2} \mathrm{H}+{ }_{1}^{3} \mathrm{H} \rightarrow{ }_{2}^{4} \mathrm{He}+{ }_{0}^{1} n+17.6 \mathrm{MeV},
$$

for each act of synthesis (fusion) of these nuclei, energy releases equal to about $17.6 \mathrm{MeV}[1,4,6]$. As a result of this nuclear reaction, such a chemical element as helium with its ${ }_{2}^{4} \mathrm{He}$ nucleus, having kinetic energy of $3.5 \mathrm{MeV}$, and a fast high-energy neutron ${ }_{0}^{1} n$, which has kinetic energy of $14.1 \mathrm{MeV}$, «born». It is necessary to remind the reader of the well-known data that the off-system energy unit used in nuclear physics $1 \mathrm{eV}=1.602 \cdot 10^{-19} \mathrm{~J}$ (one electron volt is the energy that an electron acquires, which overcomes a potential difference of one volt in the electric field) is practically equivalent to a micro-substance with absolute temperature of $11600 \mathrm{~K}$ [4]. We add that according to the laws of molecular physics, the absolute temperature of a gas (plasma) is a measure of the average kinetic energy of its molecules (atomic nuclei) [4]. In addition, we note that in order for (1) the $\mathrm{D}-\mathrm{T}$ type reaction to proceed, in the TNR core a temperature of at least $100 \cdot 10^{6} \mathrm{~K}$ should be maintained $[4,5,8]$. The reason for this is that to merge two nuclei into one, you first need to bring them closer to the distance between the forces of strong interaction, overcoming the Coulomb repulsion of their positively charged protons (from nuclear physics it is known that for all nuclei the forces of strong interaction have a radius of less than for their Coulomb repulsion [4]). For TNR, the only way to overcome these Coulomb forces is to use the energy of the thermal motion of the nuclei [4-8].

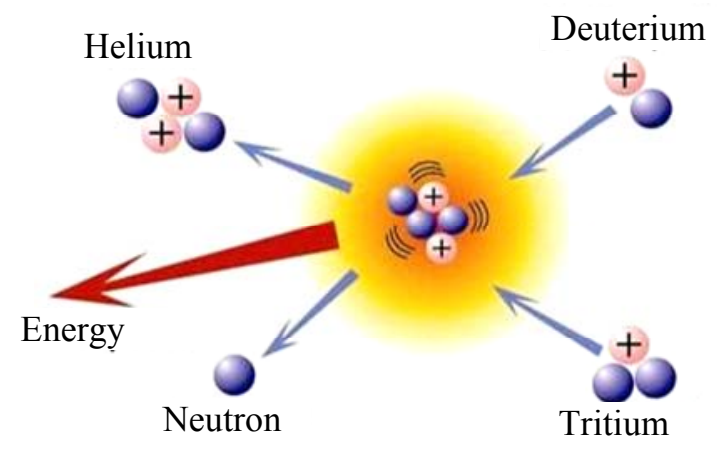

Fig. 1. Schematic representation of a promising thermonuclear synthesis reaction in TNR of deuterium D and tritium T [6]

In the course of many years of research by nuclear physicists from leading scientific centers of the world, it 
has been established that at least the following three basic conditions must be fulfilled simultaneously for a reliable flow of CTS in a high-temperature plasma (a mixture of light nuclei used) of the TNRs:

- the rate of nuclear collisions in a plasma should correspond to its temperature $T_{p}$ in the TNR chamber (in this case, for a $\mathrm{D}-\mathrm{T}$ reaction, the temperature $T_{p}>10^{8} \mathrm{~K}$ );

- the Lawson criterion formulated for a D - T type thermonuclear reaction in the form of the following mathematical relationship: $n_{p} \tau_{p}>10^{14} \mathrm{~cm}^{-3} \cdot \mathrm{s}$, where $n_{p}, \tau_{p}$ are the density and retention time of a high-temperature plasma in the active zone of the TNR, respectively;

- the criterion for «ignition» of a mixture of light nuclei.

Here we need to note that the value of $\tau_{p}$ is not the time during which a hot plasma is maintained in the TNR with temperature $T_{p}$ indicated above. It should be pointed out that the time $\tau_{p}$ of plasma confinement in the TNR is equal to the ratio of the thermal energy stored in the plasma under consideration to the power losses of this energy [9]. For a better understanding of this special material from the field of high-temperature plasma physics, let us point out that, according to the Lawson criterion at a temperature $T_{p}$ a mixture of deuterium $\mathrm{D}$ and tritium $\mathrm{T}$ in the TNR core equal to $10 \mathrm{keV}$ (approximately $116 \cdot 10^{6}[4]$ ), for flow in it (in this zone) of the CTS we need to obtain in TNR a product of the number $n_{p}$ of particles of the indicated thermonuclear fuel of $1 \mathrm{~cm}^{3}$ by the time $\tau_{p}$ of their retention (in seconds), numerically equal to at least $10^{14} \mathrm{~cm}^{-3} \cdot \mathrm{s}$. In this case, it is unimportant that a plasma with concentration of about $n_{p}=10^{14} \mathrm{~cm}^{-3}$ and its confinement time $\tau_{p}=1 \mathrm{~s}$ or with concentration $n_{p}=10^{23} \mathrm{~cm}^{-3}$ and its confinement time $\tau_{p}=1 \mathrm{~ns}$ will be in the TNR [9]. It is believed that the Lawson criterion is responsible for obtaining in the TNR an energetically favorable thermonuclear synthesis reaction in a mixture of light nuclei. The fulfillment of the plasma «ignition» criterion for the TNR means that the fraction of thermonuclear energy that remains in the plasma is enough to maintain the required temperature $T_{p}$ in it and additional heating of the plasma from light nuclei in the TNR is not required [9].

2. The initial stage of research on controlled thermonuclear synthesis. In 1950, at the suggestion of Academician of the Academy of Sciences of the USSR I.V. Kurchatov (1903-1960), Corresponding Member of the Academy of Sciences of the USSR L.A. Artsimovich (1909-1973) was appointed by the Chairman of the USSR Council of Ministers I.V. Stalin as scientific supervisor of the Soviet experimental studies on the CTS [10]. Since that time, research began in the world on the CTS. It is generally accepted that the initial idea and the first scheme of building a laboratory unit for obtaining the CTS were proposed in 1950 by a talented Soviet selftaught physicist, then serving as a sergeant for military service in the Far East of the country, O.A. Lavrentiev (1926-2011), worked for many years after the turning point for him and the whole USSR the year 1953 (the time of I.V. Stalin's death, the execution of L.P. Beria and the actual «expulsion» of this physicist by his detractorsscientists from Moscow) at the Ukrainian Institute of Physics and Technology (UPhTI, now the National Scientific Center «KhPhTI» of the National Academy of Sciences of Ukraine, Kharkiv) and which first became Candidate of Physical and Mathematical Sciences in the USSR and then Doctor of Physical and Mathematical Sciences in independent Ukraine [7, 11, 12]. A surprising fact is that it would seem that the amateur physicist O.A. Lavrentiev proposed in complete isolation on Sakhalin Island the installation scheme for the implementation of the CTS in 1951 which was refined by professional physicists then still Candidate of Physical and Mathematical Sciences A.D. Sakharov (1921-1989) and Corresponding Member of the Academy of Sciences of the USSR I.E. Tamm (1895-1971), who worked at the P.N. Lebedev Physical Institute of the Academy of Sciences of the USSR and both of them later became Academicians of the Academy of Sciences of the USSR and the Heroes of Labor for the outstanding results of the work on the USSR Atomic Project, and finally received the name TOKAMAK, which is widely known in the scientific world [11-14]. This abbreviation of purely Soviet origin is decoded as «TOroidal CAmera with MAgnetic Coils» [5, 9]. Since the 1950s, in the field of controlled synthesis, the era of tokamak installations began in the scientific physical world, which continues to this day.

We emphasize that the technical proposals of O.A. Lavrentiev on the CTS, set forth by him in a number of letters to the Central Committee of the Communist Party and personally to I.V. Stalin, served as a kind of "catalyst» for the appearance in the USSR of the government program of CTS research [15]. So, on May 5, 1951, I.V. Stalin approved the secret Resolution of the Council of Ministers of the USSR No. 1463-732cc/on «On the conduct of research and experimental work to clarify the possibility of a magnetic thermonuclear reactor» (it is now declassified) [15]. This document was the first not only in the USSR, but also the first government act in the world, indicating the beginning of the exploratory works of physicists on the CTS. It is interesting to note that the author on official business in the 2000s was fortunate enough to personally communicate with the legendary physicist O.A. Lavrentiev, who left a noticeable «trace» in domestic atomic science and technology, despite all adversities and upheavals in his rich creative life. Getting acquainted with the materials of the mid-1950s on the CTS $[12,15]$, proposed by this talented nugget man with a seven-year education, alone at the remote edge of the USSR, along with other scientists, one is struck by his intuition and abilities.

2.1. Thermonuclear tokamak installations. Fig. 2 in general form shows the scheme for constructing the thermonuclear installation TOKAMAK used at the initial stage of studies of the CTS [9-14]. 


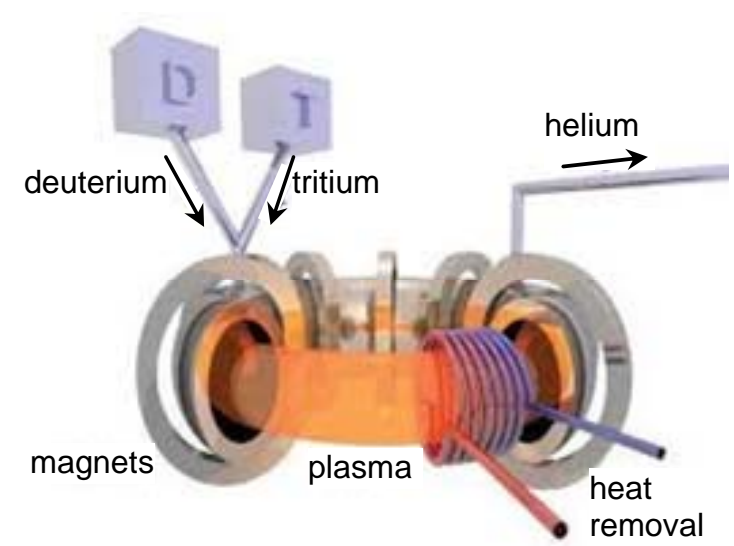

Fig. 2. Schematic representation of the TOKAMAK thermonuclear facility with superconducting coils of toroidal magnetic field, which uses in its vacuum toroidal chamber a high-temperature plasma from Mixture of interacting nuclei of deuterium $\mathrm{D}$ and tritium $\mathrm{T}$ [9]

We point out that from 1951, M.A. Leontovich (1903-1981), future Academician of the Academy of Sciences of the USSR, headed theoretical studies on the problem of the CTS in the USSR [12]. It is important to note that in 1956, by special order of the Chairman of the USSR Council of Ministers N.S. Khrushchev, works on the CTS in the USSR were completely declassified [10]. This allowed Academician of the Academy of Sciences of the USSR I.V. Kurchatov in the same 1956 when he traveled to the UK as part of a government delegation make a presentation at the British Nuclear Center (Harwell) on the first results of the CTS research obtained by Soviet physicists. This event for the West has become a real sensation (their own work on the CTS was secretly «behind the seal»). From Fig. 2 it can be seen that ringshaped superconducting coils cooled by liquid helium create a toroidal magnetic field in tokamak, isolating the high-temperature $\mathrm{D}-\mathrm{T}$ plasma from the walls of its toroidal chamber $[5,8]$. In this regard, high-temperature plasma in the TNR is not held by the walls of the toroidal chamber with a refractory blanket, which is not able to withstand its temperature of hundreds of millions of degrees, but by specially created crossed magnetic fields: toroidal and poloidal (Fig. 3). A special feature of the TOKAMAK was the use of a ring electric current flowing directly through the $\mathrm{D}-\mathrm{T}$ plasma and intended both for its ohmic heating and creating around the cord of a hot plasma of an azimuthal magnetic field necessary for its additional radial compression and reliable confinement.

According to Fig. 3 lines of force of the total magnetic field in the tokamak installation have the shape of spirals, covering the central annular axis of the plasma torus, in which the CTS reactions should occur. The Lorentz force acting on the charged particles of hot plasma (ions and electrons) in a magnetic field causes them to rotate along so-called Larmor circles around the indicated spirals-lines of force of the total magnetic field in the toroidal plasma cord [4]. The greater the magnetic flux density in the tokamak hot plasma, the smaller the Larmor radius of these particles in the mixture of reactive nuclei of thermonuclear fuel. This circumstance will prevent the plasma from spreading across the total magnetic field in its toroidal cord. It should be noted that, together with plasma particles, the considered magnetic field of a tokamak will keep charged products of a thermonuclear reaction in its «trap». If $\mathrm{D}-\mathrm{T}$ mixture is used, these products will be helium ${ }_{2}^{4} \mathrm{He}$ nuclei (alpha particles with energy of 3.5 $\mathrm{MeV}$ ) [7]. When cooled during Coulomb collisions with plasma particles, these products of $\mathrm{D}-\mathrm{T}$ reactions will transfer their energy to the plasma. This phenomenon opens up the possibility of obtaining a mode with self-sustaining thermonuclear burning in tokamaks [1].

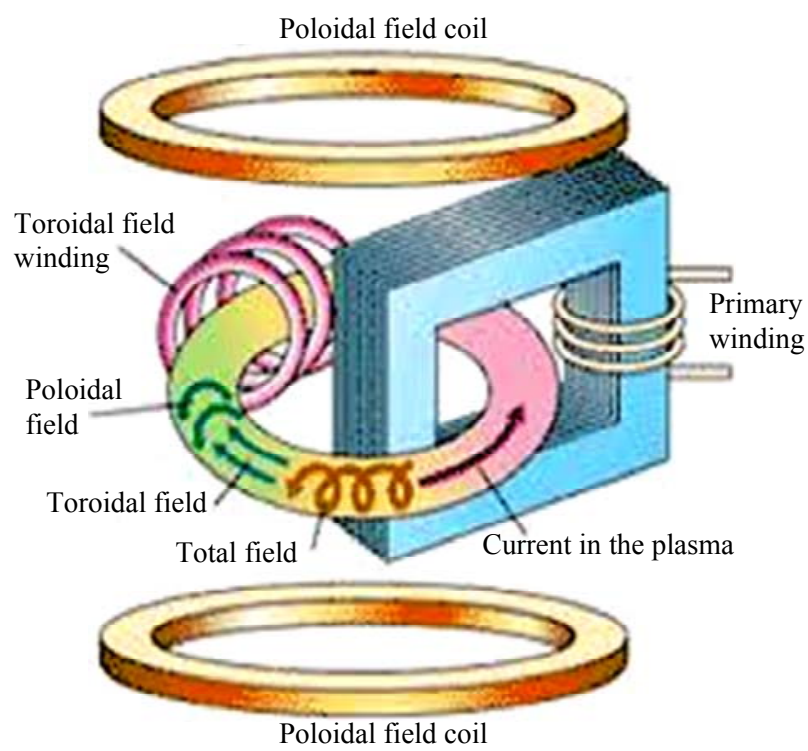

Fig. 3. An advanced scheme for constructing a TOKAMAK thermonuclear installation, containing superconducting coils of toroidal and poloidal magnetic fields, and also the excitation system in the plasma of the ring current $[1,5]$

In 1968, a group of Soviet physicists under the supervision of Academician of the Academy of Sciences of the USSR L.A. Artsimovich at the TOKAMAK-3 facility (Fig. 4), for the first time in the world, make it possible to register «thermonuclear» neutrons, «born» as a result of a nuclear reaction of the CTS in a mixture of deuterium $\mathrm{D}$ and tritium $\mathrm{T}$ nuclei [10]. The highest temperature of the $\mathrm{D}-\mathrm{T}$ plasma in a closed magnetic system («trap») of a toroidal type of the 1st generation of the Soviet tokamak installation of the TOKAMAK-3 type reached this period about $0.5 \mathrm{keV}\left(5.8 \cdot 10^{6} \mathrm{~K}\right)$ [ 1,16$]$. The principle of magnetic confinement of hot plasma in the implementation of the CTS, implemented in the scheme in Fig. 3, was also used in the creation in the 1970s of the 2nd generation of tokamak installations (T-7, $\mathrm{T}-10$ and $\mathrm{T}-11$ types) in the USSR [1]. We point out that the UPhTI-KhPhTI of the Ukrainian SSR Academy of Sciences (Kharkiv) was in the former USSR one of the leading scientific centers for the development, creation and research of experimental thermonuclear facilities.

For example, in 1978, the TOKAMAK-7 large research thermonuclear installation [7, 17] was put into operation at the KhPhTI of the Academy of Sciences of the Ukrainian SSR. In addition, this principle of building tokamaks was also applied when creating similar thermonuclear facilities abroad (for example, PLT and DIII-D types in the USA, ASDEX types in Germany, TER in France and JET-2 in Japan) [1]. At tokamaks installations of the 2nd generation, the temperature 
levels in the thermonuclear plasma reached several keV (several tens of millions of degrees), and the density $n_{p}$ of the hot plasma was $\sim 10^{20} \mathrm{~m}^{-3}$ [1]. In the $1980 \mathrm{~s}$, the 3rd generation of tokamak installations with large radius of a toroidal chamber up to $2-3 \mathrm{~m}$ and a plasma ring current of several megaamperes (for example, types JET and TORUS-SUPRA in Europe, JT60-U in Japan, TFTR in the USA and T-15 in the USSR) [1, 18] was developed. Fig. 5 shows a general view of the installation TOKAMAK-15 [18].

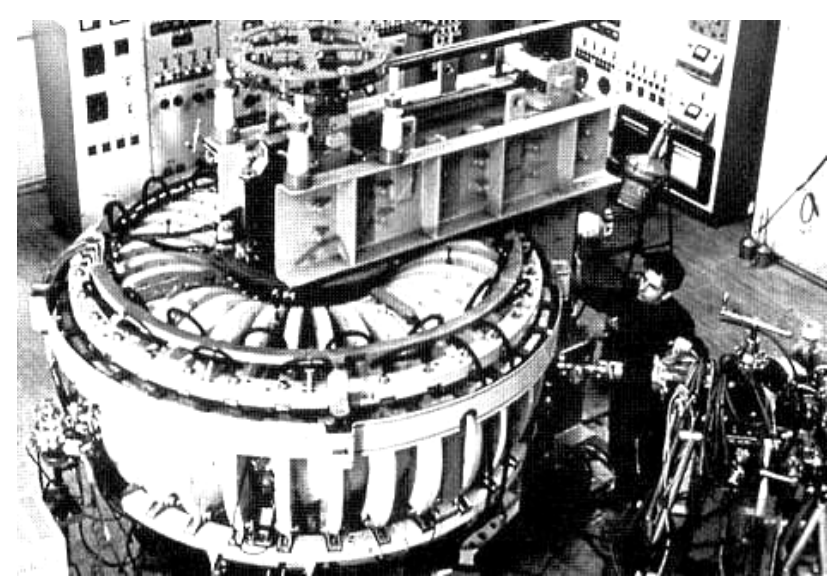

Fig. 4. General view of one of the world's first tokamak installations of the TOKAMAK-3 type built by Soviet physicists and electrical engineers at the I.V. Kurchatov Institute of Atomic Energy (1968, Moscow, USSR) [11]

Table 1 presents the main technical characteristics of the above mentioned experimental tokamaks of the 3rd generation, in which the parameter $Q_{f}=P_{\text {syn }} / P_{\text {cost }}$, where $P_{\text {syn }}, P_{\text {cost }}$ are, respectively, the values of the power of thermonuclear synthesis and the costs used, numerically did not exceed $1[1,18]$.

Note that in all thermonuclear tokamaks built as of 2017 in a number of industrialized countries of the world (Russia, Ukraine, USA, UK, Germany, France, Japan, China, Kazakhstan, etc.) in a total of up to 300, the ring megaampere current flowing in their high-temperature plasma provides its initial heating only to about $30 \cdot 10^{6} \mathrm{~K}$ $[5,14]$. Further heating of the hot plasma in these installations is performed by other physical methods [5].

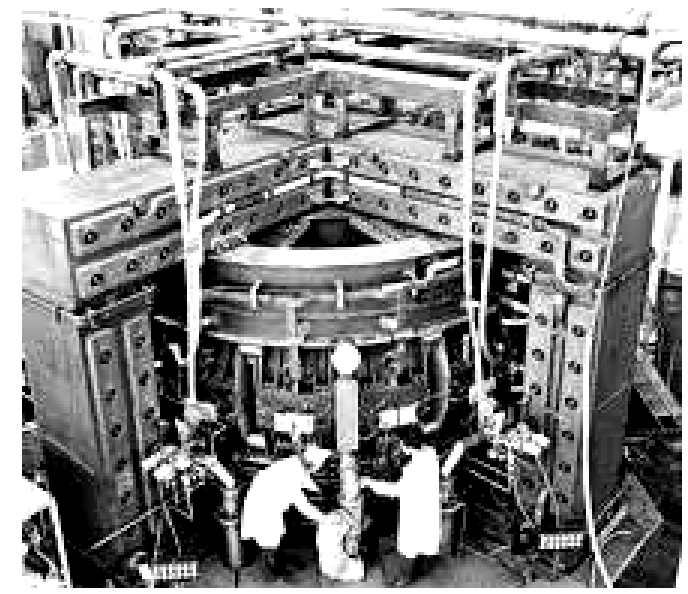

Fig. 5. General view of the largest Soviet research thermonuclear tokamak installation of the 3rd generation of the type TOKAMAK-15 (1980s, Moscow, USSR) [18]
The main technical characteristics of the world's largest tokamaks of the $3^{\text {rd }}$ generation $[1,18]$

\begin{tabular}{|l|c|c|c|c|c|}
\hline $\begin{array}{l}\text { Tokamak installation } \\
\text { type }\end{array}$ & JET & JT60-U & T-15 & TFTR & $\begin{array}{c}\text { TORUS- } \\
\text { SUPRA }\end{array}$ \\
\hline $\begin{array}{l}\text { Chamber large radius, } \\
\text { m }\end{array}$ & 3 & 3,3 & 2,4 & 2,6 & 2,4 \\
\hline $\begin{array}{l}\text { Chamber small radius, } \\
\text { m }\end{array}$ & 1 & 1 & 0,7 & 0,9 & 0,8 \\
\hline $\begin{array}{l}\text { Current in the plasma, } \\
\text { MA }\end{array}$ & 7 & 3 & 2,5 & 3 & 2 \\
\hline $\begin{array}{l}\text { Plasma heating power, } \\
\text { MW }\end{array}$ & 30 & 30 & 20 & 50 & 15 \\
\hline $\begin{array}{l}\text { Magnetic flux density } \\
\text { in the plasma, T }\end{array}$ & 3,5 & 4 & 3,5 & 6 & 4 \\
\hline
\end{tabular}

Fig. 6 shows a general view of the powerful foreign tokamak installation of the 3rd generation JET (Joint European Torus), created in 1991 by the international organization Euratom in the UK $[13,18]$.

In the tokamak of JET type, a combined heating of its D - T plasma with a volume of $100 \mathrm{~m}^{3}$ to the temperature of $150 \cdot 10^{6} \mathrm{~K}$ was used due to the injection of fast neutral particles (20 MW) into the active zone and the use of electromagnetic waves (32 MW) with frequency coinciding with rotation around the magnetic field lines in the TNR chamber of electrons and ions (electron-ion cyclotron resonance mode) [13]. As a result, for this tokamak, the Lawson criterion turned out to be only 4-5 times lower than the level of the «ignition» reaction of the mixture of light nuclei used in it $[13,19]$. We point out that for the first time at tokamaks of JET (United Kingdom) and TFTR (Test Fusion Tokamak Reactor, USA) types, large values of developed thermonuclear power in plasma were obtained during synthesis reactions in $\mathrm{D}-\mathrm{T}$ mixture: $11 \mathrm{MW}$ in TFTR and $16 \mathrm{MW}$ in JET $[1,13]$.

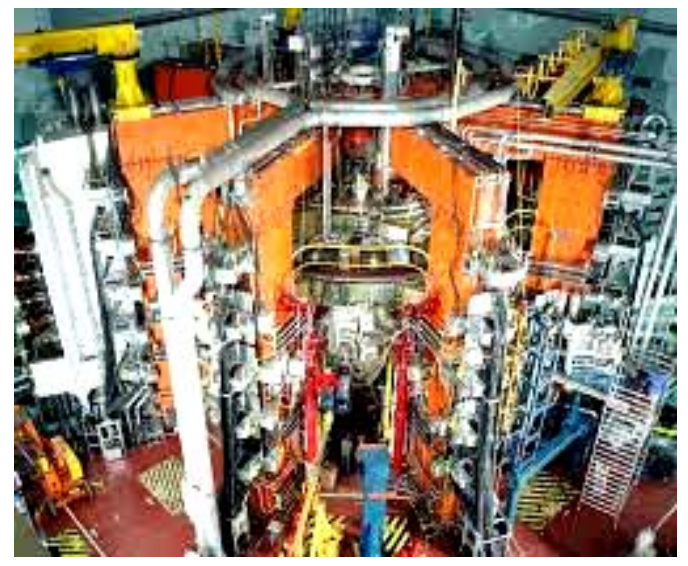

Fig. 6. General view of the world's largest operating thermonuclear tokamak JET, created by Euratom and located near Oxford in the nuclear research center Culham Lab (1997, Abingdon, UK) [18]

(Currently, the tokamak of JET type successfully continues its operation and has reached a record plasma temperature of $300 \cdot 10^{6} \mathrm{~K}$ with duration of its confinement $\tau_{p} \leq 1.2 \mathrm{~s}$ [11]. Up to 350 leading European physicists and specialists are involved in it. According to experts, the current Brexit and the possible exit of Great Britain from Euratom (the European Atomic Energy Community 
responsible for the safe use of nuclear energy) will significantly complicate further operation of the world's largest tokamak of JET type [13]. In addition, the decommissioning of the JET-type tokamak will lead to the formation of about $3000 \mathrm{~m}^{3}$ of radioactive waste, the disposal of which will cost the European taxpayer up to USD 360 million [13].

An important problem for tokamak installations for a long time was the need to create the circular current in hot plasma. For this purpose, a massive magnetic core was installed inside their torus (see Fig. 3-6), the magnetic flux of which continuously changed in time [9]. The change of this flux in accordance with the laws of electrodynamics leads to the creation in the considered region of an eddy electric field, which induces a corresponding current in the plasma cord. This current had to flow continuously in the plasma in one direction, which was naturally impossible to implement. Therefore, the required current in the plasma was maintained only for a limited time, measured in fractions of a second, and in the limit by several seconds [9]. In the course of research on tokamak installations, by electrophysicists a so-called bootstrap current was detected, which appeared in plasma without the influence of an external eddy electric field. In addition, methods have been developed for cyclotron heating of plasma particles, at the same time causing in it to flow the necessary circular current. All this together gave a potential opportunity for long-term maintenance of hot plasma in the vacuum chamber of the experimental TNR. Currently, the record belongs to the large tokamak of the type «Tore Supra» (nuclear center in Cadarache, France), in which the plasma «burned» for up to $360 \mathrm{~s}[9,19]$.

Taking into account the above information, it can be stated that the invention and research of tokamaks, requiring the attraction of huge creative forces of people and financial resources in a number of countries, allowed humanity to nevertheless approach the practical development of such an unlimited source of energy as CTS $[5,14]$.

2.2. Thermonuclear stellarator installations. In the tokamak plasma torus, plasma ignition occurs due to the formation in it of a ring electric current of the megaampere range (see Fig. 3 and Table 1). Because of this, moving electrons and ions are formed in the torus («donut») of the tokamak installation, forming azimuthal magnetic fields. These fields strive to destroy the main toroidal magnetic field of the installation and destabilize its plasma cord. It is important to note that the circular current in the plasma in modern tokamaks is supported by a superhigh-frequency electric field created by the primary winding of an inductor located in the central region of the toroidal chamber. In this case, the plasma cord inside the chamber plays the role of a secondary single-turn winding of a step-down transformer. For the first time in the world, the thermonuclear stellarator facility was proposed in 1951 by the American physicist L. Spitzer [20]. This type of research thermonuclear reactor received its name from the Latin word «stella»«star» [21]. Indeed, the planned temperature level in the active zone of this thermonuclear installation should have exceeded the temperature $\left(\sim 15 \cdot 10^{6} \mathrm{~K}\right)$ inside the core of a star like the Sun. Unlike a thermonuclear tokamak facility, in this thermonuclear stellarator unit plasma from a mixture of light nuclei (for example, from a $\mathrm{D}-\mathrm{T}$ mixture) arising in a toroidal vacuum chamber is heated and held only by external electric currents and magnetic fields (Fig. 7) [9].

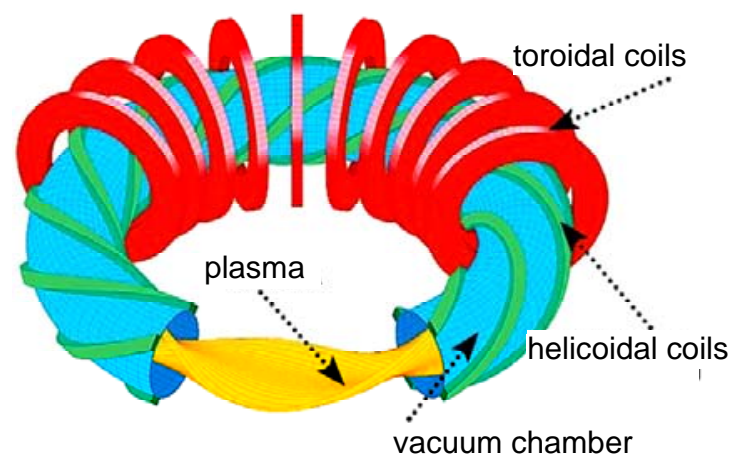

Fig. 7. Schematic diagram of the construction of a research thermonuclear stellarator installation containing a toroidal vacuum chamber with a plasma of light nuclei, helicoidal and toroidal superconducting coils for the formation of a complexshaped magnetic field [9]

In this regard, the design of the stellarator required the use of superconducting helicoidal coils of complex shape (see Fig. 7). Exploratory studies of electrophysicists have shown that another possible way to create a thermonuclear stellarator installation may be the use of a vacuum chamber with a hot plasma not in the shape of a circular ring (torus) as in Fig. 7, but in the shape of the «eight» or even more complex shape - the «crumpled donut» (Fig. 8) [9].

The external magnetic field in such designs of the stellarator is formed of a «sly» shape, which ensures the stability of the plasma generated in its vacuum chamber. Compared with a tokamak, such a stellarator design is more complex and requires quite complex numerical calculations for the geometry of its magnetic field to be calculated.

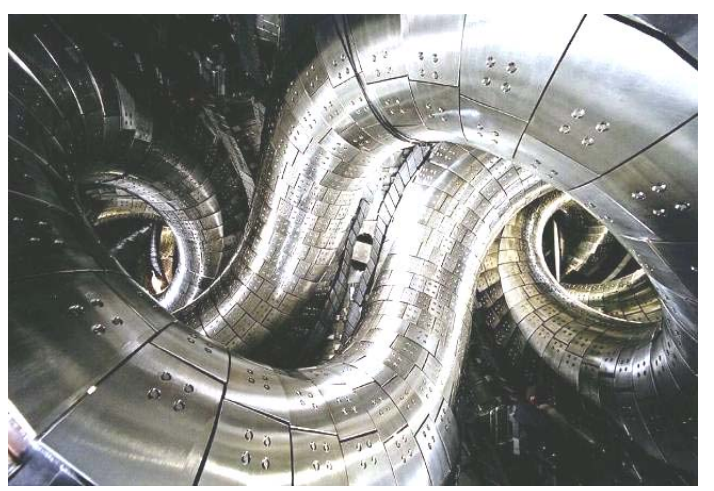

Fig. 8. General view of a working vacuum metal chamber with a hot plasma of an experimental thermonuclear stellarator installation curved in the shape of complex 3D serpentine configuration («crumpled donut») [9]

In the second half of the 1950s, on the initiative of the supervisor of the USSR Atomic Project, Academician of the Academy of Sciences of the USSR I.V. Kurchatov In the UPhTI (the Physics and Technology Institute PhTI which had become by this time) of the Ukrainian 
SSR Academy of Sciences, research was started on a new scientific field related to the study of high-temperature plasma and the CTS $[17,22]$. Academician of the Academy of Sciences of the Ukrainian SSR K.D. Sinelnikov (1901-1966) was appointed scientific supervisor of thermonuclear research at the PhTI of the Ukrainian SSR Academy of Sciences (Kharkiv) [22]. The apogee of these works was the creation in 1968 of a powerful experimental thermonuclear installation with superconducting magnets of the Uragan-2 type at the indicated Ukrainian institute (Fig. 9) [22, 23].

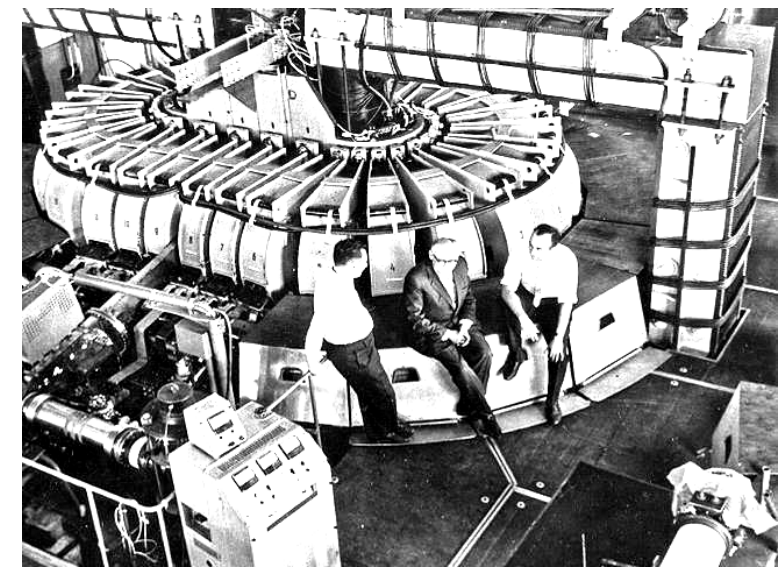

Fig. 9. General view of a powerful Uragan-2 type thermonuclear installation developed by the PhTI of the Ukrainian SSR Academy of Sciences (from left to right: famous Kharkiv physicists V.A. Suprunenko, A.I. Akhiezer and V.T. Tolok; 1968; PhTI of the Ukrainian SSR Academy of Sciences; Kharkiv) [22]

We also point out that in the $1980 \mathrm{~s}$, in the framework of experimental research on the CTS in the USSR at the KhPhTI of the Academy of Sciences of the Ukrainian SSR (Kharkiv), a superconducting torsatron of stellarator type Crystal-2 with magnetic flux density up to $5 \mathrm{~T}$ and stored magnetic energy up to $1 \mathrm{MJ}$ in its vacuum chamber of complex geometric shape with a hot plasma $[7,24]$ was created. Fig. 10 shows a general view of a modern experimental thermonuclear stellarator installation with a camera made in the shape of a «crumpled donut» [6].

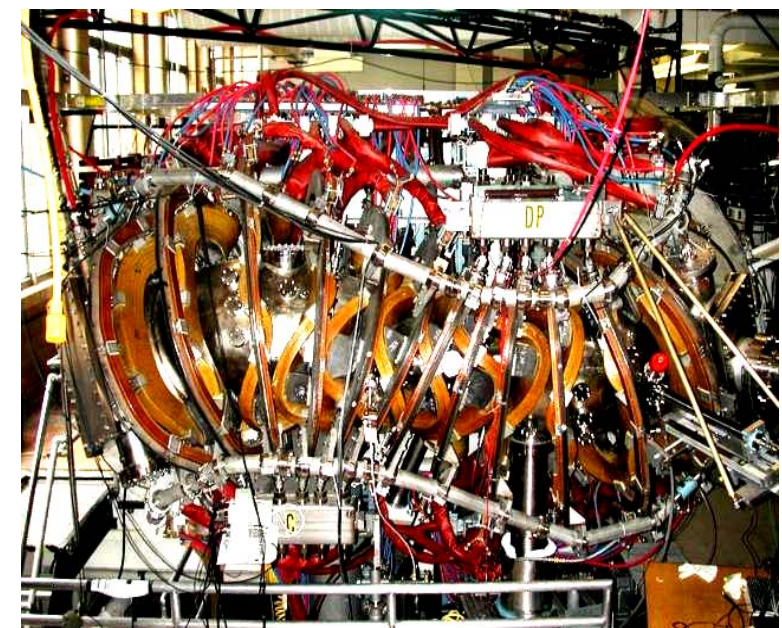

Fig. 10. External view of one of the laboratory constructions of a research thermonuclear stellarator containing a vacuum chamber in the shape of a «crumpled donut» $[6,13]$
Despite the fact that today in the stellarator units, the retention time for hot plasma is less, and the cost of their construction is higher than for tokamak installations, research in the world of this type of TNR is actively continuing $[1,20]$. One of the reasons for this is that the behavior of high-temperature plasma in them is quieter and more stable. This leads to a higher working life of the inner wall of the vacuum chamber with hot plasma. With the commercialization of the CTS, this technical fact can play a decisive role in choosing the design of the TNR, so it will determine its service life as part of a thermonuclear power plant (TNPP). In this regard, the designs of powerful thermonuclear stellarators being created at the present time have been substantially simplified. Their vacuum chambers in the shape of «crumpled donuts» had to be abandoned. They look like tokamaks [9].

3. The modern stage of research in controlled thermonuclear synthesis. As was noted above in subsection 2.1, experimental studies on the CTS at the largest JET tokamak-type thermonuclear facility are currently being actively pursued as part of the Euratom program $[1,13]$. With the reached «life» time of the hot plasma in the vacuum chamber of the tokamak of JET type up to $1.2 \mathrm{~s}$, its energy parameter $Q_{f}$ was numerically 0.65 [12]. It can be seen that the European nuclear physicists on the JET-type tokamak came close to the «threshold», beyond which a positive energy balance begins when implementing CTS. Experimental data on thermonuclear power and temperature in the $\mathrm{D}-\mathrm{T}$ mixture (respectively, up to $16 \mathrm{MW}$ and 300 million $\mathrm{K}[1,13]$ ) obtained at this TNR give us some hope for the reality of the creation in the 21 st century of industrial TNR and practical receiving energy from CTS $\left(Q_{P}>1\right)$.

In Germany, at the Max Planck Institute for Plasma Physics (Greifswald) on December 10, 2015, the world's largest thermonuclear «Wendelstein 7-X» type thermonuclear stellarator installation (Fig. 11) was successfully put into its pilot operation which cost the German state EUR 1.06 billion [20].

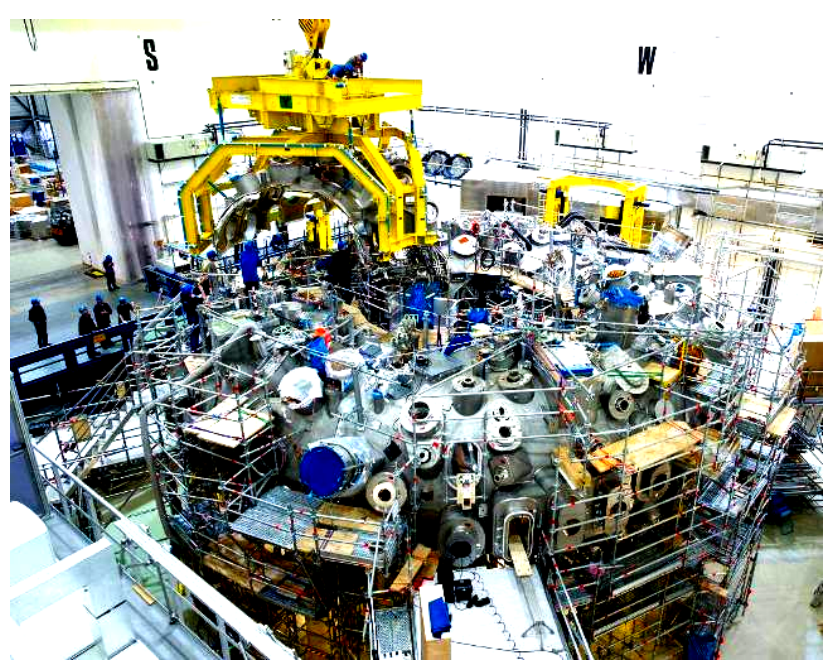

Fig. 11. General view of the construction site at the time of final assembly of unique electrophysical devices of the world's largest experimental thermonuclear stellarator installation «Wendelstein 7-X» (2015, M. Planck Institute for Plasma Physics, Greifswald, Germany) [20] 
In this stellarator, the large radius of the vacuum chamber with plasma is $5.5 \mathrm{~m}$, and its small radius is 0.53 $\mathrm{m}$. The volume of its hot plasma is $30 \mathrm{~m}^{3}$, and its density will reach a level of $3 \cdot 10^{20} \mathrm{~m}^{-3}$ [20]. This experimental TNR contains 50 superconducting niobium-titanium coils of $3.5 \mathrm{~m}$ high, the total weight of which is about 425 tons. The magnetic flux density in the working vacuum chamber of the TNR reaches $3 \mathrm{~T}$, and the plasma temperature maintained by such a magnetic field will be up to $130 \cdot 10^{6} \mathrm{~K}$ [20]. The entire construction of the world's largest stellarator is surrounded by a cryostat (durable heat insulating shell) with a diameter of $16 \mathrm{~m}$. A major technical problem in the construction of a «Wendelstein 7-X» type stellarator was a shortage of superconducting magnets with special geometry and cooled by liquid helium [20]. In 2003, during the tests, up to $30 \%$ of the magnets were rejected and returned to the supplier. The project by 2007 was on the verge of closure. The long-term construction led to an almost 2-time increase in the planned cost of the stellarator (from EUR 500 to 1,060 million) [20].

In the first experiments on «Wendelstein 7-X» type stellarator, physicists was able to heat one milligram of gaseous helium to a temperature of $1 \cdot 10^{6} \mathrm{~K}$ using a 1.3 MW microwave external electromagnetic pulse and hold the resulting hot plasma for $0.1 \mathrm{~s}$ [20]. The immediate work plans for this facility are a gradual increase in the power of the source of electromagnetic radiation and an increase in the temperature of the plasma investigated in the chamber [20].

The German research TNR stellarator «Wendelstein $7-\mathrm{X} »$ is not a competitor to the world's largest tokamak ITER (International Thermonuclear Experimental Reactor) currently under construction in France (nuclear center Cadarache), which will be discussed below in section 7. One of the goals of the German project in the field of controlled synthesis is to work out the confinement mode of hot hydrogen plasma to half an hour and bring the parameter $\beta$, equal to the ratio of the plasma pressure to the pressure of the magnetic field holding it, to (0.04-0.05). Another goal of this important high-tech project is to develop a number of promising thermonuclear technologies [20].

In the mid-1960s, a fundamentally new approach appeared as an alternative to magnetic confinement of hot plasma in the field of the CTS: its inertial confinement based on the use of high-power lasers - sources of directed ultra short-wave electromagnetic radiation $[4,9]$. This approach initially used small target balls of frozen $\mathrm{D}$ - $\mathrm{T}$ fuel, uniformly irradiated from all sides by a multitude of laser beams. The irregular heating of such thermonuclear fuel required a significant change in the design of the ball target [5]. Currently, these fusion fuel targets are placed inside a hollow spherical hohlraum chamber (from the German word «hohlraum» - «cavity») with holes through which laser beams fall into it. In addition, in the laser-pulse technology of the CTS, they began to use crystals that convert infrared laser radiation into ultraviolet radiation. This ultraviolet radiation is absorbed by a thin layer of the target hohlraum material, heated to an enormous temperature and emitted soft Xrays [9]. This P-radiation is absorbed by the thinnest layer of the thermonuclear fuel capsule, which leads to the flow of the CTS in it.

Fig. 12 shows a general view of a thermonuclear installation that uses laser pulse technology of microexplosions of thermonuclear fuel enclosed in separate capsules in its TNR $[9,18]$.

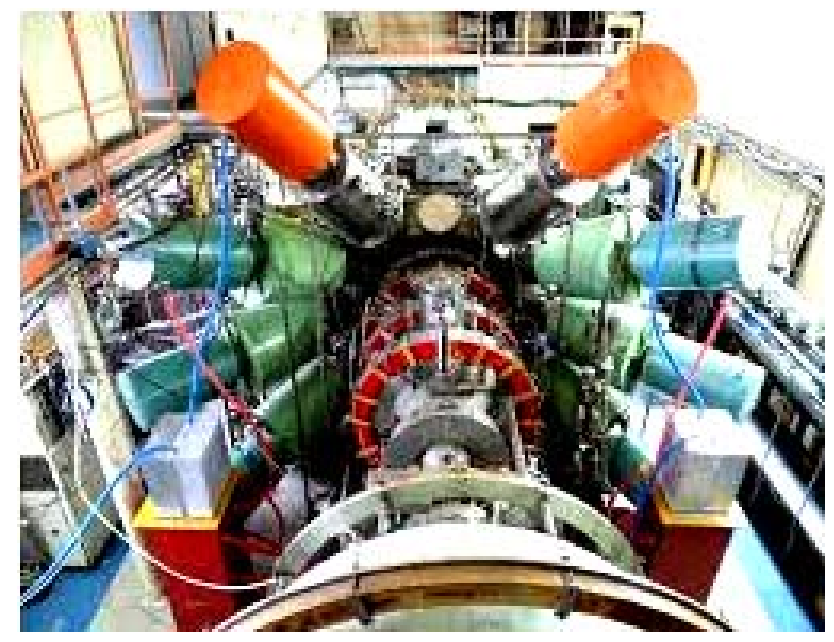

Fig. 12. General view of an experimental TNR of a modern thermonuclear installation using laser-pulse technology for microexplosions of D-T fuel capsules $[5,18]$

At present, this promising technology for the implementation of the CTS due to the simultaneous volumetric impact on spherical target microcapsules of frozen thermonuclear $\mathrm{D}-\mathrm{T}$ fuel of high-power laser pulses is at the stage of conducting laboratory experiments $[9,25]$. It should be noted that over the past ten years there has been a qualitative leap in the development of world laser technology, which has managed to increase the efficiency of high-power lasers by a factor of ten [9]. Moreover, their power at the same time managed to increase hundreds and thousands of times [9]. Therefore, it can be said that the inertial version of the CTS in the world does not «stand» in place, but is successfully developing [5, 18, 25].

In 2006, the first successful tests of an experimental advanced superconducting tokamak of the EAST type (Experimental Advanced Superconducting Tokamak) were carried out in China, the general view of which is shown in Fig. 13 [5, 18]. In 2007, the first «break-even» CTS in the world, characterized by the parameter $Q_{f}=1.25$, equal to the ratio of obtained in the toroidal chamber of this reactor that is a deep modernized design of the Russian tokamak of HT-7 type thermonuclear energy to spent on receiving and combined heating to ultra-high temperature (about $100 \cdot 10^{6} \mathrm{~K}$ ) of a plasma string of electrons and relatively light heavy and superheavy isotopes of hydrogen (nuclei of deuterium D and tritium T) [5] was carried out. In the near future, Chinese nuclear physicists will try to bring the $Q_{f}$ parameter to a value of $\sim 50$ [5]. At present, the experimental TNR of EAST type is also used in the framework of research activities related to the development and creation of a more powerful international tokamak of ITER type. 


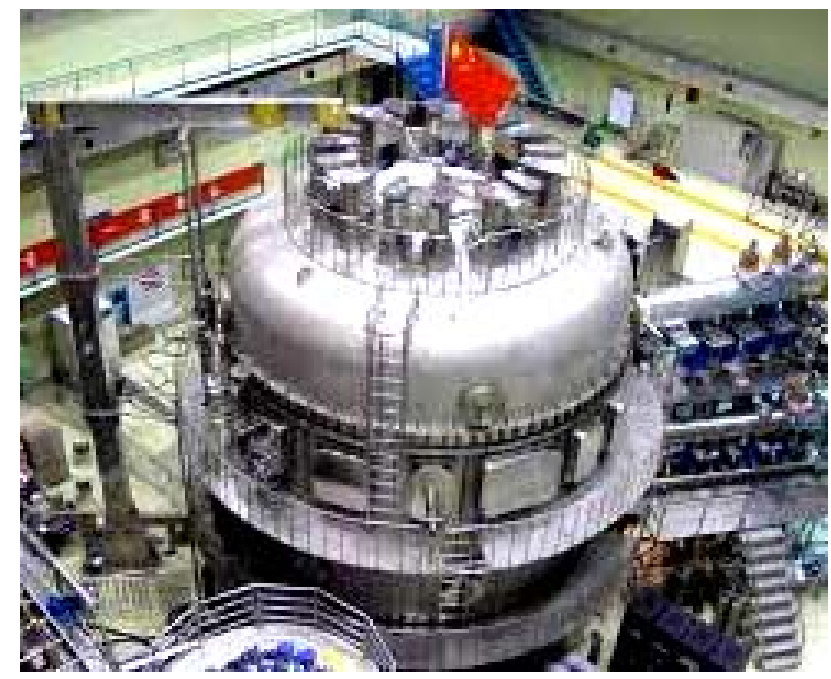

Fig. 13. General view of a powerful experimental TNR of EAST type, created according to the tokamak scheme in the People's Republic of China (2006, Institute of Plasma Physics,

Chinese Academy of Sciences, Hefei, Anhui Province) [5, 18]

4. The main problems in the creation of the TNR and the shortcomings of the TNR. Let us further dwell on the TOKAMAK design of the TNR which is the most studied and advanced in the world now [5, 14]. For tokamak installations, in which thermonuclear fuel with density of up to $10^{20} \mathrm{~m}^{-3}$ must be heated to temperature of $(100-300) \cdot 10^{6} \mathrm{~K}$, the main disadvantages and problems in creating industrial TNR based on them are the following $[5,19,26]$ :

- the instability of a hot plasma (the plasma cord in the toroidal chamber tends to be thinner somewhere, thicker somewhere, or interrupted somewhere else with the cessation of the flow of the ring megaampere current). The use of a poloidal magnetic field (see Fig. 3) and an increase in the geometric dimensions of the vacuum chamber became possible proven ways to increase the stability of plasma combustion. The improved plasma confinement mode open by physicists will also contribute to the above mentioned stability, when at high power of its additional heating the losses of hot plasma energy sharply decreases (two or more times) [20];

- the main scientific problem for tokamak installations is that, as the pressure in the hot plasma increases, complex and dangerous instabilities arise in it, leading to an unstable operating mode of the TNR (physicists will have to take this path without fail, since the rate of fusion of light nuclei at a given plasma temperature is directly proportional to the square of its pressure);

- the high cost of tritium ${ }_{1}^{3} \mathrm{H}$, a superheavy radioactive isotope of hydrogen ${ }_{1}^{1} \mathrm{H}$ with a half-life of 12.3 years $[1,4]$ ( $1 \mathrm{~kg}$ of this substance was worth about USD 30 million by 2010 [27]). In 2014, the world stock of tritium was about $20 \mathrm{~kg}$, with its annual consumption in the world of about $7 \mathrm{~kg}$ [27]. For the future put into operation of the tokamak of ITER type being constructed in France, it will take about $3 \mathrm{~kg}$ of tritium to charge all of its tritium subsystems, as well as about $1 \mathrm{~kg}$ of tritium for each year of its operation [27];

- the minimum power of the TNR should be hundreds and thousands of megawatts (the main reasons for this are that the hot plasma in the reactor loses a lot of energy for electromagnetic radiation, and its vacuum chamber must have relatively large geometrical dimensions in order to ensure the stability of the plasma cord behavior in it);

- the high cost of the Tokamak type TNR (for example, the creation of an experimental ITER type TNR with $1500 \mathrm{MW}$ thermonuclear power will cost the participants of an international project about EUR 15 billion which is unacceptable today for an industrial CTS reactor installed at the TNPP);

- the presence of powerful neutron radiation in the TNR, which negatively affects its working life (for comparison, we point out that the neutron flux in the TNR is up to ten times more powerful than a similar flux in the NR). In this regard, the expected service life of the TNR can be no more than 5 years instead of 50 years characteristic of NR;

- specialists have no confidence in the operation of industrial TNRs based on their construction according to the principle of tokamak (up to the present, not a single tokamak worked even for several hours, not to mention the years typical of industrial reactors; there is no certainty that materials of the blanket of the inner wall of the vacuum chamber of the reactor is able to withstand the effects of hot plasma for a long time; there is also no confidence in the thermal and mechanical resistance of a number of other structural materials of the reactor experiencing prolonged exposure to intense flux of fast high-energy neutrons and powerful flux of electromagnetic radiation of particles of its hightemperature plasma);

- the design of the TNR, based on the tokamak scheme, is today quite complex (therefore, nuclear physicists and power engineers have a problematic task of special importance - ensuring the high reliability of operation of TNR as a part of the TNPP; its design and construction tasks require that whole complex of various complicated technological problems from a number of branches of knowledge should be rigorously solved).

5. Thermonuclear fuel and the main types of nuclear reactions used in TNR. As is well known, hot plasma in the TNR, using magnetic confinement of the initial products of the CTS, has a low density (of the order of $10^{20} \mathrm{~m}^{-3}[1,5]$ ). This density of hot plasma is about $10^{5}$ times less than the density of atoms and molecules in the air under normal atmospheric conditions [4]. In this regard, the Lawson criterion for tokamaks is achieved due to a good retention of thermal energy in their chamber and, accordingly, a large energy «life time» of their hot plasma. Therefore, a relatively small amount of thermonuclear fuel is required for the operation of the TNR. For example, for the largest ITER-type TNR tokamak with the specified density of the fusion gas mixture in its chamber, the initial thermonuclear cycle of the CTS requires an initial fuel of only $(0.5-1) \mathrm{g}[5,19]$. Note for reference that to heat $0.5 \mathrm{~g}$ of conventional ${ }_{1}^{1} \mathrm{H}$ hydrogen protium to temperature of $100 \cdot 10^{6} \mathrm{~K}$, it is necessary to expend as much energy as it needs to heat ordinary $\mathrm{H}_{2} \mathrm{O}$ water with a volume of 1861 to its boiling temperature of $100^{\circ} \mathrm{C}$ [19]. At present, the main types of 
nuclear reactions in CTS, which determine the choice of thermonuclear fuel, are the following $[1,5,8]$ :

- $\mathrm{D}+\mathrm{T} \rightarrow{ }_{2}^{4} \mathrm{He}(3.5 \mathrm{MeV})+{ }_{0}^{1} n(14.1 \mathrm{MeV})$;

- $\mathrm{D}+\mathrm{D} \rightarrow{ }_{2}^{3} \mathrm{He}(0.82 \mathrm{MeV})+{ }_{0}{ }^{1} n(2.45 \mathrm{MeV})$;

- $\mathrm{D}+\mathrm{D} \rightarrow \mathrm{T}(1.01 \mathrm{MeV})+{ }_{1}^{1} p(3.02 \mathrm{MeV})$;

- $\mathrm{D}+{ }_{2}^{3} \mathrm{He} \rightarrow{ }_{2}^{4} \mathrm{He}(3.6 \mathrm{MeV})+{ }_{1}^{1} p(14.7 \mathrm{MeV})$;

- ${ }_{3}^{6} \mathrm{Li}+{ }_{0}^{1} n \rightarrow{ }_{2}^{4} \mathrm{He}+\mathrm{T}+4.8 \mathrm{MeV}$.

In the above nuclear reactions involving deuterium $\mathrm{D}$ and tritium T, which are of particular interest for CTS, the symbol ${ }_{2}^{3} \mathrm{He}$ denotes the light isotope of ordinary helium ${ }_{2}^{4} \mathrm{He},{ }_{0}^{1} n$ is the fast neutron, ${ }_{3}^{6} \mathrm{Li}$ is the light isotope of natural lithium ${ }_{3}^{7} \mathrm{Li}$, and ${ }_{1}^{1} p$ is the stable proton [4]. From these nuclear reactions it can be seen that all of them occur with the release of energy in the form of the kinetic energy of the products of these reactions flying in all directions of the TNR core. The last nuclear reaction plays a special role in the CTS. It is used in the industrial production of unstable tritium $\mathrm{T}$ (in the liquefied state, tritium is 6 times lighter than water $\mathrm{H}_{2} \mathrm{O}$ [4]), which does not exist in nature in the free state (due to its relatively fast radioactive $\beta$-decay [5]). From the analysis of these nuclear reactions, it follows that the first reaction of the type $(\mathrm{D}+\mathrm{T})$ is the most «easy» for its implementation (for its flow in the working chamber of the TNR, the temperature of about 100 million $\mathrm{K}$ is required) [19]. For reactions of synthesis of the type $(D+D)$, approximately the same ultrahigh temperatures are required, but they proceed about 100 times slower than reactions of the type $(\mathrm{D}+\mathrm{T})$. In addition, the energy released during their flow is much less (about 5 times) than in the deuterium-tritium synthesis reaction. Nuclear reactions of the type $\left(\mathrm{D}+{ }_{2}^{3} \mathrm{He}\right)$ go faster than competing reactions of the type $(D+D)$. However, for their realization it is required to create limiting temperatures in the working chamber of a powerful TNR - about 1 billion K [19]. Therefore, we can conclude that for industrial use of the CTS, only nuclear fusion reactions of the type $(D+T)$ are even remotely accessible to mankind with all their shortcomings (for example, the difficulties of obtaining radioactive tritium ${ }_{1}^{3} \mathrm{H}$ using the presented fifth nuclear reaction and radioactivity induced by fast neutrons from their course in used in the construction of the cores of the TNR materials) [19]. In this regard, it is expected that in the coming decades (possibly centuries), in the industrial application of CTS in powerful TNR of a particular design, only a mixture of heavy (deuterium ${ }_{1}^{2} \mathrm{H}$ ) and superheavy (tritium ${ }_{1}^{3} \mathrm{H}$ ) hydrogen isotope ${ }_{1}^{1} \mathrm{H}$ (protium) will be used as thermonuclear fuel $[5,14,19]$.

Fig. 14 shows a schematic diagram of the production of electricity at the future TNPP using in its powerful TNR the considered TCS in a mixture of light nuclei of deuterium D and tritium T [1].

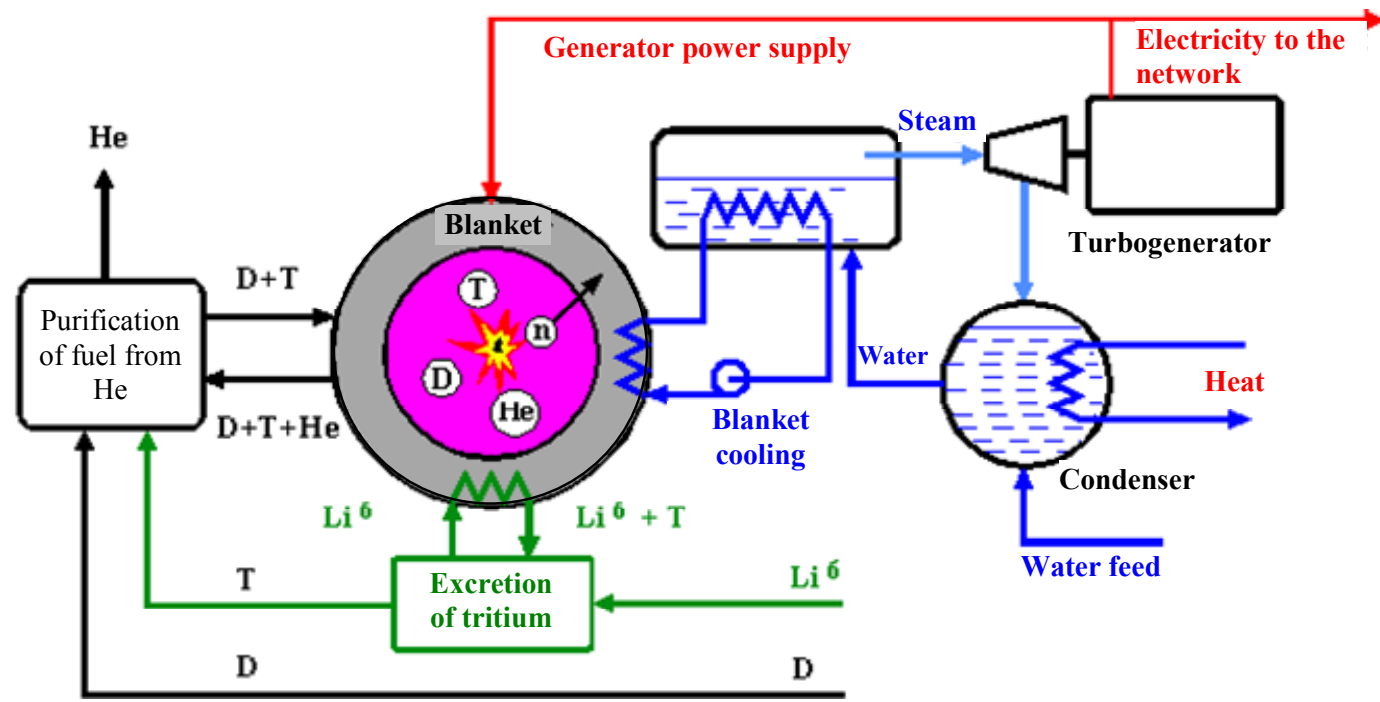

Fig. 14. Diagram of industrial production of electric power on a TNPP using large-sized TNR of controlled thermonuclear synthesis of light nuclei of deuterium $\mathrm{D}$ and tritium $\mathrm{T}[1,5]$

According to this scheme, the energy of thermonuclear reactions occurring in the deuteriumtritium plasma of the TNR chamber, mainly due to the intense flow of high-energy neutrons ${ }_{0}^{1} n$, is removed from the reactor core and absorbed by the massive refractory blanket (up to $1 \mathrm{~m}$ thickness) of the vacuum chamber case. The released thermal energy in the TNR blanket is removed by superheated coolant (for example, distilled water $\mathrm{H}_{2} \mathrm{O}$ ) of the primary reactor cooling circuit, which gives its heat in the steam generator to the liquid coolant (for example, the same $\mathrm{H}_{2} \mathrm{O}$ water purified from the impurities) of the second reactor circuit. Further, according to the classical scheme of operation of energy devices of a thermal power plant or NPP, superheated steam formed in the second circuit of the TNR is directed to the blades of a steam turbine rotating a massive steel shaft-rotor of a synchronous turbogenerator, producing a corresponding electromotive force and, accordingly, electric power in the windings of its stator.

Presented in Fig. 14 TNR requires supplying its core with deuterium $\mathrm{D}$ and tritium T. Deuterium D is produced industrially from ordinary natural water $\mathrm{H}_{2} \mathrm{O}$ (it contains about $0.015 \%$ of this heavy isotope of hydrogen in the form of heavy water $\left.\mathrm{D}_{2} \mathrm{O}[1,25]\right)$. As for tritium $\mathrm{T}$, it is planned to obtain it with the help of the ${ }_{3}^{6} \mathrm{Li}$ lithium isotope introduced into the composition of the blanket of the TNR chamber - the massive shell surrounding the hot plasma $[1,27]$. The ${ }_{3}^{6} \mathrm{Li}$ lithium isotope, entering according to the above fifth exothermic (releasing energy and heat accordingly) nuclear reaction with fast high- 
energy neutrons ${ }_{0}^{1} n$ (with their kinetic energy up to 14.1 MeV [1, 14]), will produce as a result of its nuclear decay ions of helium ${ }_{2}^{4} \mathrm{He}$ and tritium $\mathrm{T}$. The hydrogen isotope under consideration, after its separation from the products of the indicated nuclear interaction, is fed into a fusion fuel mixer, from which deuterium $\mathrm{D}$ and tritium $\mathrm{T}$ are discretely fed in a frozen state directly to the TNR camera. The ${ }_{2}^{4} \mathrm{He}$ helium nuclei (alpha particles) formed in the core of the reactor are removed from the working chamber of the TNR, deionized, cleaned from thermonuclear fuel and pumped into the tanks for their further technical use (see Fig. 14). Therefore, it is possible to say that for the scheme of constructing a TNPP with a TNR shown in fig. 14, deuterium D and lithium isotope ${ }_{3}^{6} \mathrm{Li}$ are used as fuel. Note that when obtaining tritium $\mathrm{T}$, natural lithium ${ }_{3}^{7} \mathrm{Li}$ can be used instead of lithium isotope ${ }_{3}^{6} \mathrm{Li}$ in a TNR camera blanket. Here, as a result of its endothermic (with energy and, accordingly, heat absorption) nuclear interaction with fast high-energy neutrons ${ }_{0}^{1} n$, nuclei of helium ${ }_{2}^{4} \mathrm{He}$, tritium $\mathrm{T}$ and one additional neutron ${ }_{0}^{1} n$ are formed [1, 18]. It should be noted that lithium isotopes ${ }_{3}^{6} \mathrm{Li}$ и ${ }_{3}^{7} \mathrm{Li}$, capable of producing the required for the TNPP and its TNR tritium $\mathrm{T}$, are quite widespread in the surrounding nature (at its percentage ratio as 7.5/92.5 [1, 4]). According to experts, one TNR with electrical power of $1000 \mathrm{MW}$ will burn in its core about $100 \mathrm{~kg}$ of deuterium D and $300 \mathrm{~kg}$ of ${ }_{3}^{6} \mathrm{Li}$ lithium isotope per year [1]. If we assume that in the $21 \mathrm{st}$ century, TNPPs around the world will produce approximately $5 \cdot 10^{20} \mathrm{~J} /$ year (half of the future electricity needs of mankind), then the annual consumption of deuterium $\mathrm{D}$ and ${ }_{3}^{6} \mathrm{Li}$ lithium isotope will be only 1,500 and 4,500 tons respectively [1]. With such a global annual consumption of deuterium $\mathrm{D}$ and lithium isotope ${ }_{3}^{6} \mathrm{Li}$ on future TNPPs, these minerals on planet Earth will last for many millions of years $[1,5]$.

6. Radiation safety of TNR and TNPP. Maintaining a positive energy balance in the TOKAMAK type TNR requires constant and delicate control of the plasma «burning» process, as well as the strictly synchronized operation of all the main systems of such a reactor. In the TNR, built on the basis of the tokamak installation, the failure in the operation of any of its systems leads either to a loss of stability in the plasma cord, or to its contamination with impurities followed by cooling of the plasma and eventually to the breakdown of its «burning» [1]. In this regard, the difficulties in ensuring the sustainability of the CTS process in such TNR play a positive role for the safety of the TNR itself. At the same time, in any type of TNR structures, the mode of uncontrolled growth of its power is excluded. The retreat in the TNR from the mode of the steady flow of light nuclei in its mixture of the TCS to any direction immediately leads to the breakdown of the «burning» of the plasma cord and the cessation of nuclear reactions in it. Therefore, the TNR with magnetic plasma confinement is characterized by internal safety [1]. In the course of the operation of the TNR, radioactive elements accumulate in its active zone, which can pose a certain radiation hazard to the personnel serving it, the population of the surrounding areas of the TNPP and the environment. It should be noted that the fuel used in the TNR in the form of deuterium $\mathrm{D}$ and lithium isotope ${ }_{3}^{6} \mathrm{Li}$ is not radioactive.
Not radioactive and the final product from the CTS in the TNR - helium ${ }_{2}^{4} \mathrm{He}$. In the TNR using $\mathrm{D}-\mathrm{T}$ nuclear reactions, the main sources of radioactivity are: first, tritium $\mathrm{T}$, which is involved in the fuel cycle of the reactor; secondly, induced by fast high-energy neutrons produced in the process of the CTS in its chamber, radioactivity in the structural materials of the reactor (especially in the wall of the blanket of the chamber in contact with the plasma through a magnetic field) $[1,5]$. To reduce the artificial radioactivity of the blanket wall, it is required to choose for it special materials resistant to neutron radiation. The results of the research show that in the case of manufacturing the specified wall of a blanket from a vanadium-titanium alloy or silicon carbide, it (the wall) after stopping the reactor loses its radioactivity to the level of ore of natural uranium ${ }_{92}^{238} \mathrm{U}$ in about 30 years [1]. We should not forget about the radioactive corrosion products present in the heat-transfer fluid of the primary cooling circuit of the reactor vessel. Compared to the NR of fission of heavy nuclei, which are currently used at powerful nuclear power plants, the TNR has a much greater radiation safety $[1,5]$.

7. Development and creation of an international thermonuclear experimental reactor of the ITER type. In 1985, a number of leading countries of the world (USSR, USA, France, Great Britain, Japan, etc.) launched a project to develop the largest International Thermonuclear Experimental Reactor (ITER) with electrical power of up to $1500 \mathrm{MW}[1,25-27]$. For the basis of such ITER, the leading nuclear scientists of the world and the scientific and administrative leaders of this international project adopted a deeply improved design of a powerful thermonuclear installation of the type TOKAMAK $[1,27]$. The TNR of the ITER type is planned to be put into trial operation in 2025 [1, 25-27]. Fig. 15 shows a general schematic view of this world's largest TNR using the construction scheme described in subsection 2.1 of a deeply refined classical tokamak $[14,27]$.

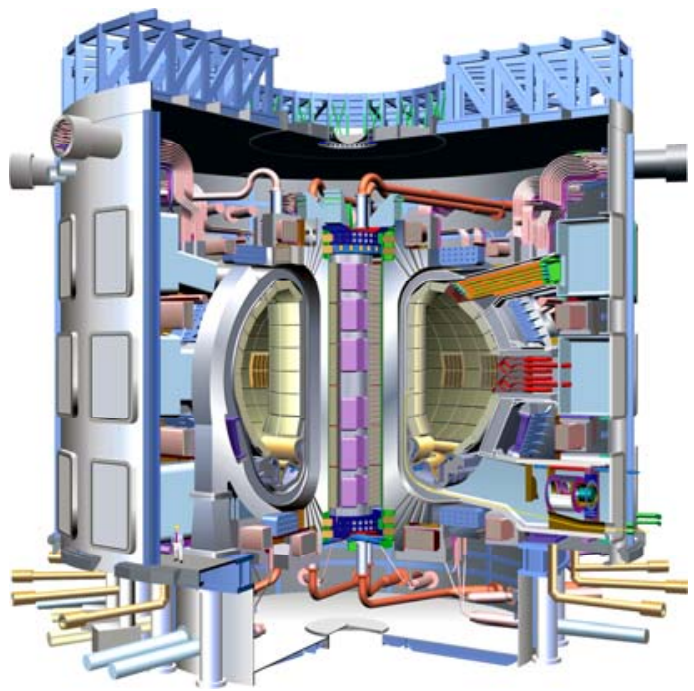

Fig. 15. Schematic 3D view in section of the International Thermonuclear Experimental Reactor of ITER type (International Thermonuclear Experimental Reactor - ITER), currently under construction in the framework of the largest international scientific and technical project of modernity (costing approximately EUR 15 billion in 2017) in the south of France (Provence) in the nuclear research center of Cadarache (60 km from Marseille) [14, 27] 
Fig. 16 shows a general view of the working toroidal chamber of this powerful experimental tokamak reactor $[14,27]$.

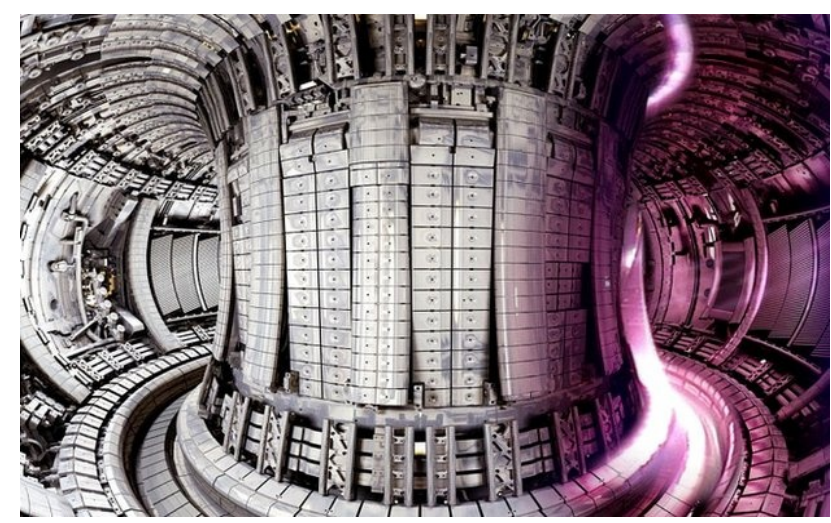

Fig. 16. General view from the inside of a layout of a toroidal vacuum chamber with a refractory massive blanket of a largesize TNR of the ITER type under construction in France [14, 27]

The following main systems and devices will be part of the ITER-type TNR [26, 27]:

- the reactor magnetic system containing 18 superconducting toroidal coils (conductors - $\mathrm{Nb}_{3} \mathrm{Sn}$; current - $68 \mathrm{kA}$; magnetic flux density - $11.8 \mathrm{~T}$; accumulated field energy - $41 \mathrm{GJ}$; weight -6540 tons; cost - EUR 323 million), 6 superconducting poloidal field coils (conductors - $\mathrm{NbTi}$; current - $52 \mathrm{kA}$; magnetic flux density $-6 \mathrm{~T}$; accumulated field energy $-4 \mathrm{GJ}$; weight 2163 tons; cost - EUR 122 million) and central solenoid (conductors - $\mathrm{Nb}_{3} \mathrm{Sn}$; current - $46 \mathrm{kA}$; magnetic flux density - $13 \mathrm{~T}$; accumulated field energy - 6.4 GJ; mass 974 tons; cost - EUR 135 million);

- the vacuum toroidal chamber with a double wall (made of stainless steel $316 \mathrm{LN}$ in the American assortment and $03 \mathrm{X} 16 \mathrm{H} 15 \mathrm{M} 3$ in the Russian assortment; the large radius of the chamber is $6.2 \mathrm{~m}$; the small radius of the chamber is $2 \mathrm{~m}$; the height of the chamber is up to $11 \mathrm{~m}$; the volume of the chamber cavities up to $1400 \mathrm{~m}^{3}$; mass up to 5000 tons; for trapping CTS products and cleaning the plasma from contamination, the chamber is equipped with a diverter from the bottom; distilled water circulates between the walls of the chamber to cool the chamber; the inner wall of the chamber is equipped with a blanket to protect against powerful thermal and neutron radiation);

- the blanket of the vacuum chamber which for ease of maintenance contains 440 cassettes (three cassettes contain ${ }_{3}^{6} \mathrm{Li}$ lithium isotope to produce ${ }_{1}^{3} \mathrm{H}$ tritium), each of which has a removable beryllium wall up to $10 \mathrm{~mm}$ thickness facing the plasma and a copper case reinforced with stainless steel (dimensions of each cassette amount to $1 \times 1.5 \mathrm{~m}$, and weight up to $4.6 \mathrm{t}$ );

- the electron-cyclotron resonant plasma heater of the ECRH type (Electron Cyclotron Resonance Heating), designed for the initial heating of the gas mixture entering the chamber; 24 gyrotrons each with power of $1 \mathrm{MW}$, operating frequency of $170 \mathrm{GHz}$ and pulse duration of up to $500 \mathrm{~s}$ are used as sources of electromagnetic energy; to enter energy from the gyrotrons into the chamber, there are special «windows» made of polycrystalline artificial diamond (the diameter of each diamond disk is $1.1 \mathrm{~mm}$ thickness is $80 \mathrm{~mm}$ ); the choice of diamond was due to the fact that it is transparent to microwave radiation, durable, radiation resistant and has thermal conductivity five times higher than that of copper; through each diamond «window» of the chamber power up to $500 \mathrm{MW} / \mathrm{m}^{2}$ will pass;

- the ion-cyclotron resonant plasma heater of ICRH type (Ion Cyclotron Resonance Heating), designed to heat plasma ions; as a source of RF radiation (with frequency of up to $55 \mathrm{MHz}$ ), a powerful radio frequency generator on tetrodes is used, transmitting electromagnetic energy through waveguides and antennas to the TNR camera;

- the injector of neutral atoms, «firing» into the plasma cord of the reactor a powerful beam of deuterium $\mathrm{D}$ atoms, which were actually ionized to their nuclei and accelerated in a cyclotron to the kinetic energy of $1 \mathrm{MeV}$; before being fed into the TNR chamber, the accelerated deuterium nuclei $\mathrm{D}$ are deionized in cells filled with gas (here they capture electrons from the gas molecules and recombine; after these cells, the deuterium nuclei $\mathrm{D}$ that did not have time to recombine are deflected by the magnetic field and diverted to special braking targets); two powerful injectors of neutral atoms are planned to be installed at the ITER reactor (with a total power consumption of $55 \mathrm{MW}$ ), each of which is capable of introducing up to $16 \mathrm{MW}$ of thermal energy into the hot plasma of the vacuum chamber of the reactor;

- the cryostat, which is the largest device of the reactor (has a stainless steel shell with volume of $16,000 \mathrm{~m}^{3}$, height of $29.3 \mathrm{~m}$, diameter of $28.6 \mathrm{~m}$ and mass of 3850 tons); in addition to purely mechanical functions (the support for the reactor elements and their protection from damage) and the thermo-insulating function, the cryostat performs the role of a vacuum «thermos» and a barrier between the internal TNR cavity and the external environment; a cryostat to reduce the adverse effect on the environment of the intense neutron radiation of the reactor will be outside surrounded by a «blanket» of special concrete of $2 \mathrm{~m}$ thickness that plays the role of bioprotection (Bioshield) of the TNR;

- the fuel system supplying the reactor chamber core having the Lawson criterion $n_{p} \tau_{p}>10^{20} \mathrm{~m}^{-3} \cdot \mathrm{s}$, a mixture of hydrogen isotopes - deuterium $\mathrm{D}$ and tritium $\mathrm{T}$; at the beginning of the operation of the TNR, this mixture in a gaseous state through the injection system under low pressure enters the evacuated chamber, where it heats up, ionizes and turns into a plasma; then an «ice» gun is used to inject an additional deuterium-tritium fuel into the plasma cord, pulsing the frozen granules of the $\mathrm{D}-\mathrm{T}$ mixture into this cord under pressure at speed of $\sim 1000 \mathrm{~m} / \mathrm{s}$; at each current time, the reactor chamber should contain no more than $1 \mathrm{~g}$ of the specified fuel;

- the vacuum system designed to evacuate the cavity of the chamber (the pressure in it should not exceed $10^{-9}$ from normal atmospheric pressure) and other elements of the TNR (for example, transmission lines into the chamber of microwave electromagnetic radiation, injection systems into the chamber of powerful flows of neutral atoms, etc.); it is planned that for vacuum 
preparation of all subsystems of the reactor, a similar system will take about 48 hours;

- the cryogenic system that serves to cool the currentcarrying parts of the magnetic system of the reactor to the superconducting state; it consists of nitrogen (provides thermal load of $1300 \mathrm{~kW}$ at temperature of boiling nitrogen of $80 \mathrm{~K}$ ) and helium (provides thermal load of $65 \mathrm{~kW}$ with power consumption of refrigerating machines of $16 \mathrm{MW}$ ) contours; the helium supply in the system is 25 tons, which is stored in a liquid (at temperature of $4 \mathrm{~K}$ ) and gaseous (at temperature of $80 \mathrm{~K}$ ) state in special «tanks»; the total length of cryogenic lines is $\sim 3 \mathrm{~km}$;

- reactor power supply system, connected by a $1 \mathrm{~km}$ long power line to the $400 \mathrm{kV}$ French industrial network; for internal needs of the TNR, the supplied mains voltage decreases to 22 and $66 \mathrm{kV}$; there are two internal power supply networks for the TNR equipment power supply: the first one of type SSEN (Steady State Electrical Network) - a network of constant power (its consumers do not need power «surges»; it has four transformers with weight of $90 \mathrm{t}$ each); the second one of type PPEN (Pulsed Power Electrical Network) is a variable power network (its consumers require enormous power at the time of plasma «ignition» in the TNR toroidal chamber; its consumers include the central solenoid of the magnetic system of the reactor, the systems of cyclotron heating of the plasma, the TNR control systems; this network includes three transformers 240 tons each);

- the water cooling system of the reactor, designed to remove excess heat from the massive walls of the blanket and the chamber diverter; according to expert estimates, at the time of the ignition of the thermonuclear reaction in the chamber (with peak power of $1.1 \mathrm{GW}$ ), the blanket wall will heat up to $240{ }^{\circ} \mathrm{C}$ and the tungsten wall of the divertor up to $2000{ }^{\circ} \mathrm{C}$; this system will also be used for cooling the ICRH-type plasma radiofrequency heater, the cryogenic system, etc.

Table 2 shows the main technical characteristics of the experimental ITER-type TNR selected in a long-term development process [26, 27].

Corrected in the course of work the main technica Table 2 characteristics of the world's largest ITER-type TNR being built in France in the framework of the international project [26, 27]

\begin{tabular}{|c|l|c|}
\hline 1 & Total radius of the reactor structure, $\mathrm{m}$ & 10.7 \\
\hline 2 & Reactor structure height, $\mathrm{m}$ & 30 \\
\hline 3 & Vacuum chamber large radius, $\mathrm{m}$ & 6.2 \\
\hline 4 & Vacuum chamber small radius, $\mathrm{m}$ & 2 \\
\hline 5 & Hot plasma volume in the reactor, $\mathrm{m}^{3}$ & 837 \\
\hline 6 & Magnetic flux density in the chamber, $\mathrm{T}$ & 5.3 \\
\hline 7 & Current in the plasma cord, MA & 15 \\
\hline 8 & Power of the external plasma heating, MW & 73 \\
\hline 9 & $\begin{array}{l}\text { Average thermonuclear power in the pulse during } \\
\text { one operating cycle, MW }\end{array}$ & 500 \\
\hline 10 & $\begin{array}{l}\text { Peak thermonuclear power in the pulse during one } \\
\text { operating cycle, MW }\end{array}$ & 1100 \\
\hline 11 & Power gain & 10 \\
\hline 12 & Average hot plasma temperature, $\mathrm{K}$ & $150 \cdot 10^{6}$ \\
\hline 13 & Pulse duration in the cycle, $\mathrm{s}$ & $>400$ \\
\hline
\end{tabular}

The gigantism of the constructed ITER-type TNR is underlined by its total weight of about 23 thousand tons (for comparison, we point out that the weight of the Eiffel Tower in Paris is about 7.3 thousand tons) [27, 28]. This reactor is not the largest in terms of financial costs of an international project. Thus, the development, construction and maintenance of the International Space Station (the ISS project) cost donor countries one and a half times more expensive than work on the ITER project with an estimated cost of EUR 15 billion [27, 28]. It is planned that the first phase of experiments at the ITER reactor should be completed by retaining in its chamber the hot plasma heated to a temperature of $150 \cdot 10^{6} \mathrm{~K}$ for up to 17 min with the parameter $Q_{P} \geq 10$ and the released thermonuclear power of at least $500 \mathrm{MW}$ [27]. The second phase of experiments at the ITER should be completed with a continuous operation mode of this tokamak. The ITER project should demonstrate the capabilities of the CTS and help explore thermonuclear technologies for their further use for peaceful commercial purposes. The results of experimental work on the ITERtype TNR should lead specialists to develop an industrial TNR capable of operating at the TNPP.

8. Possible prospects for the creation of industrial TNR, TNPP and in the development of global thermonuclear energy. The currently available critical assessments by experts of the energy market indicate that the question of the profitability of the CTS in industrial conditions is still open [5]. In addition, there are more radical authoritative opinions about a possible future of the thermonuclear energy. For example, in 2006, Academician of Russian Academy of Sciences Yu.A.Trutnev (First Deputy Head of the RPhNCVNIIEPh, Sarov), responding to a question about the prospects of the CTS problem, said the following [29]: «... I do not deal with this problem and do not believe in it. I believe that all these works are the satisfaction by the scientists of their curiosity at the expense of the state. Research in the field of thermonuclear energy is ongoing, but I do not believe that thermonuclear energy will become a source of energy even in a somewhat distant future». Nuclear power engineering, based on fission reactions of heavy nuclei by slow or fast neutrons, with all its disadvantages, is a serious alternative to thermonuclear power engineering $[1,2]$. Supporters of the CTS believe that the final phase of experimental work at the ITER-type tokamak reactor should be the development of a prototype of the industrial reactor of the DEMO type, which will demonstrate the practical suitability of the solutions and structural materials used in it. The most optimistic forecasts for the time of completion of the phase of work on the TNR of the DEMO type are the year 2045 [5, 28]. Following the DEMO project, the design of the industrial TNR can begin. It is assumed that the world's first industrial TNPP can be created by $2055[5,27]$. Experts believe that a TNPP with electrical power of $1000 \mathrm{MW}$ in terms of radiation hazard would be equivalent to a fission reactor of heavy nuclei in natural uranium ${ }_{92}^{238} \mathrm{U}$, containing up to $0.71 \%$ of the uranium isotope ${ }_{92}^{235} \mathrm{U}$ fusing in a chain manner with a power of $1 \mathrm{~kW}$ [4] (this is a typical example of a University research NR) $[5,11]$. With all 
attractiveness of the TNPP, the question of their industrial application will become clearer in the world, probably only by the middle of the 21 st century. By this time, still unresolved problems from the physics of hightemperature plasma of tokamaks will be studied and irrefutable experimental data will emerge about the possibility of creating an industrial design of the TNR, without which it is impossible to understand the prospects for CTS development, creation of TNPPs and thermonuclear energy in general.

\section{Conclusions.}

1. From presented brief scientific and technical review of research in the leading countries of the world in the field of the CTS, actively conducted since the 1950s, and the thermonuclear energy of the distant future, it follows that the CTS of light nuclei (for example, hydrogen isotopes such as deuterium $\mathrm{D}$ and tritium ) is fundamentally possible in terrestrial conditions. It can be stated that as of the end of 2017, the leading countries of the world conducted a huge complex of nuclear physics research in the field of the CTS. Various designs of TNR with magnetic and inertial confinement of hot plasma have been created and experimentally investigated. The record levels of temperature and retention time of hot plasma in $\mathrm{D}-\mathrm{T}$ mixture in the experimental TNRs reached $300 \cdot 10^{6} \mathrm{~K}$ and $6 \mathrm{~min}$. Here, the main technical task all over the world for nuclear physicists and power engineers is the development and creation of an industrial design of the TNR that could economically compete with other powerful sources of energy known to mankind. At present, such a TNR design in the world does not yet exist. For its development, a complex of exploratory experimental work is being carried out, the apogee of which is to become the world's largest TNR tokamak of the type ITER, now being constructed in the framework of an international project in the south of France.

2. In the near future (possibly by 2030), specialists can obtain at the TNR (for example, on the same ITER-type tokamak) its energy indicator $Q_{f}=10$ (the thermonuclear energy obtained in the reactor is 10 times higher than the energy spent on hot plasma preparation and retention). Despite this achievement, the first industrial designs of the TNR will be much more expensive than uranium NRs of the same power (due to their more complex structure, large dimensions, the use of superconducting electromagnets and a shorter service life). Therefore, in the 21 st century, they are unlikely to be able to win competition from NRs using neutron-fission reactions involving heavy nuclei of isotopes of uranium ${ }_{92}^{238} \mathrm{U}$, plutonium ${ }_{94}{ }^{244} \mathrm{Pu}$ and thorium ${ }_{90}{ }^{232} \mathrm{Th}$.

3. In the author's opinion, as an electrical physicist scientist, despite such modest prospects for practical application of the CTS in this century, for the humanity taking into account its steady development in the third millennium and the mastery of new higher knowledge in basic science and technology, it is imperative to continue to work hard in the interest of progress in the field of peaceful development of thermonuclear energy.

\section{REFERENCES}

1. http://thermonuclear.narod.ru/rev.html (Velikhov E.P., Putvinskiy S.V. Thermonuclear power engineering. Status and role is in a long-term prospect. Lecture from 22.10.1999 y. in Energy Center of the World Federation of Scientists). (Rus).

2. Baranov M.I. An anthology of the distinguished achievements in science and technique. Part 44: Traditional power engineering. Nuclear power stations: retrospective view, state and prospects of their development. Electrical engineering \& electromechanics, 2018, no.3, pp. 3-16. doi: 10.20998/2074272X.2018.3.01.

3. Baranov M.I. An anthology of the distinguished achievements in science and technique. Part 32: Alternative energy: state and prospects of development. Electrical engineering \& electromechanics, 2016, no.3, pp. 3-16. doi: 10.20998/2074-272X.2016.3.01.

4. Kuz'michev V.E. Zakony i formuly fiziki [Laws and formulas of physics]. Kiev, Naukova Dumka Publ., 1989. 864 p. (Rus).

5. Available at: https://en.wikipedia.org/wiki/Fusion_power (accessed 15 April 2017).

6. Available at: http://greensource.ru/vidyjenergii/termojadernaja-jenergija.html (accessed 22 May 2017). (Rus).

7. Baranov M.I. Antologiia vydaiushchikhsia dostizhenii $v$ nauke $i$ tekhnike: Monografiia $v$ 3-h tomakh. Tom 1. [An anthology of outstanding achievements in science and technology: Monographs in 3 vols. Vol.1]. Kharkov, NTMT Publ., 2011. 311 p. (Rus).

8. Artsimovich L.A. Upravlyaemye termoyadernye reaktsii [Guided thermonuclear reactions]. Moscow, Fizmatlit Publ., 1961. 467 p. (Rus).

9. Available at: https://www.popmech.ru/science/12621zvezdy-na-zemle-termoyad/\# (accessed 08 October 2016). (Rus).

10. Available

at:

http://www.biblioatom.ru/founders/artsimovich_lev_andreevich (accessed 25 March 2017). (Rus).

11. http://reactors.narod.ru/pub/therm_nucl/therm_nucl.htm. (Rus).

12. Bondarenko B.D. Role played by O A Lavrent'ev in the formulation of the problem and the initiation of research into controlled nuclear fusion in the USSR. Uspekhi Fizicheskih Nauk, 2001, vol.171, no.8, pp. 886-894. (Rus). doi: 10.3367/UFNr.0171.200108q.0886.

13. Available at: http://www.atomicenergy.ru/news/2016/12/02/70677 (accessed 06 February 2017). (Rus).

14. Available at: http://lurkmore.to//Термоядерный_синтез (accessed 13 April 2017). (Rus).

15. Goncharov G.A. The 50th anniversary of the beginning of research in the USSR on the potential creation of a nuclear fusion reactor. Uspekhi Fizicheskih Nauk, 2001, vol.171, no.8, pp. 894-901. (Rus). doi: 10.3367/ufnr.0171.200108r.0894.

16. Artsimovich L.A., Mirnov S.V., Strelkov V.S. Research of the ohmic heating of plasma on the torus setting «TOKAMAK3». Atomic energy, 1964, vol.17, no.8, pp. 170-176. (Rus).

17. Khramov Yu.A. Istoriia fiziki [History of Physics]. Kiev, Feniks Publ., 2006. 1176 p. (Rus).

18. Available

https:/www.google.com.ua/search?q=ua/search?q=termojdernaya elektrostanciya (accessed 15 May 2017). (Rus).

19. Available at: https://geektimes.ru/post/167523 (accessed 28 June 2017). (Rus).

20. Available at: https://lenta.ru/articles/2015/12/11/wendelstein7x/ (accessed 04 May 2017). (Rus).

21. Bol'shoj illjustrirovannyj slovar' inostrannyh slov [Large illustrated dictionary of foreign words]. Moscow, Russkie slovari Publ., 2004. 957 p. (Rus).

22. Baranov M.I. Antologija vydajushhihsja dostizhenij v nauke i tehnike: Monografija v 3-h tomah. Tom 3 [An anthology of the distinguished achievements in science and technique: 
Monograph in 3 volumes. Volume 3]. Kharkiv, PhPB Panov A.N. Publ., 2016. 415 p. (Rus).

23. Available at: http://www.kipt.kharkov.ua (accessed 10 March 2017). (Rus).

24. Yuferov V.B., Druy O.S., Skibenko E.I., Kholod Yu.V., Chernyy O.V., Il'icheva V.O., Mufel' E.V., Rybalko A.N. Superconducting magnetic systems of difficult form and highdensity of a transport current. Electrical engineering \& electromechanics, 2003, no.2, pp.81-89. (Rus).

25. Available at: http://foraenergy.ru/termoyadernaya-energetika (accessed 09 September 2016). (Rus).

26. Available

https://www.gazeta.ru/science/2011/09/05 a 3756341.shtml

(accessed 19 October 2016). (Rus).

27. Available at: https://en.wikipedia.org/wiki/ITER (accessed

22 January 2017).

How to cite this article:

Baranov M.I. An anthology of the distinguished achievements in science and technique. Part 46: Thermonuclear power engineering. Thermonuclear reactors and power plants: retrospective view of investigations of the controlled thermonuclear synthesis, their state-of-the-art and future. Electrical engineering \& electromechanics, 2018, no.6, pp. 3-17. doi: 10.20998/2074-272X.2018.6.01.
28. Available at: https://lenta.ru/articles/2014/05/28/iter/ (accessed 29 April 2017). (Rus).

29. Osadin B.A. Tokamafia: from Bringing Opponents into Engineering, 2010, no.4, pp. 2-13. (Rus).

Received 06.03.2018

M.I. Baranov, Doctor of Technical Science, Professor,

Scientific-\&-Research Planning-\&-Design Institute «Molniya», National Technical University «Kharkiv Polytechnic Institute», 47, Shevchenko Str., Kharkiv, 61013, Ukraine, phone +380 577076841 ,

e-mail: baranovmi@kpi.kharkov.ua Discredit to a Global Monopoly. History of Science and 